\title{
MPhil Scholars' Views about the Use of Humor in English Language Classroom in Quetta, Balochistan, Pakistan
}

\author{
Rabbia Nayyar ${ }^{1}$ \& Muhammad Zeeshan ${ }^{1}$ \\ ${ }^{1}$ Department of Linguistics (English), University of Balochistan, Quetta, Pakistan \\ Correspondence: Rabbia Nayyar, Department of Linguistics (English), University of Balochistan, Sariab Road, \\ Quetta, Balochistan, Pakistan. Tel: 92-334-238-8994.E-mail: rubianayyar@yahoo.com
}

Received: November 9, 2016

Accepted: December 9, 2016 Online Published: January 19, 2017

doi:10.5539/ijel.v7n2p134

URL: http://dx.doi.org/10.5539/ijel.v7n2p134

\begin{abstract}
The element of humor is one of the important elements in a person's social life and when used in the English language classroom by teachers, it could affect the students' learning. This study investigated MPhil scholars' views being student and teacher regarding the use of humor in English language classroom. The research was qualitative using purposive sampling. The sample consisted of eight female MPhil scholars of English department of two universities in Quetta, Balochistan, Pakistan. Interviews and observations were the instruments used for data collection. The data were analyzed through content analysis and for this purpose NVivo (Version 10) was used. The participants' views and teaching practices suggested humor to be beneficial in the English language classrooms to motivate students. The results of this study recommend using humor in English language classroom as it may make teaching more effective. The future research directions are also suggested.
\end{abstract}

Keywords: English language classroom, humor, motivation

\section{Introduction}

Enhancing the ways of students' learning process has been a priority of teachers. For this purpose, the teachers do experiments and explore the new ideas for improving students' level of learning. Usually, teaching is considered to be a serious job; therefore, teachers are supposed to follow traditional teaching style (teaching without incorporating humor) in class. On the other hand, the findings from the past studies suggest using humor in teaching.

Salehi \& Hesabi (2014) conducted a mixed method study of 60 female participants of EFL institute Isfahan. Salehi \& Hesabi (2014) found that the participants showed more positive approach towards learning in the context where humor was added instead of learning through the traditional teaching style. Likewise, Motlagh, Motallebzade, \& Fatemi (2014) conducted an experimental study of 58 students in Shiraz, Iran. The sample was selected from the population of 100 male intermediate students after a proficiency test. The purpose of the study was to measure the effect of humor on Iranian EFL learners' reading comprehension ability and on their motivation. The findings revealed that the result of the experimental group was significantly different from the control group. The addition of humor in teaching provided much better result than teaching without its addition. Moreover, addition of humor improved students' motivation in reading comprehension (Motlagh et al., 2014).

The past studies indicate that the addition of humor could work as a motivational tool for students. This study intended to explore the views and the teaching practices of participants regarding humor as a motivational tool. This is the first time that an empirical study is conducted regarding the use of humor in English language classrooms in Quetta, Balochistan, Pakistan. The results of this study may help the instructors to know the importance of humor in class through the participants' perspective.

\section{Literature Review}

Numerous studies have been conducted so far on the use of humor in English language classrooms, few of them are reviewed here. Kosiczky \& Mullen (2013) conducted a qualitative study to probe teacher leaders' perceptions about the use of humor in the high school classroom and to find how humor could help in students' learning, and building teacher-student relationship. Nine secondary level teacher leaders from various subject areas in North Carolina School were observed and interviewed. Two focus-group sessions were also conducted for data 
collection. Out of nine teacher leaders, three were male and six were female. They were the teachers of different subjects: career technical education, drama, English, mathematics, social studies, dance, science, and life skills. The findings from observation revealed that incorporating humor in class seemed to create a very friendly and relaxing climate in the class. This helped students interact easily. Learning environment became enjoyable. Even in the interviews, teachers mentioned that humor is important to create an enjoyable climate. Some teachers teased individual students in a light humorous way which brought smile on their faces that showed a sign of positive relationship between teachers and students. Light humor was used to encourage the students. Students seemed happy in those classes where humor was added more frequently. Teachers were of the opinion that the element of humor became the reason of communication. All teachers relied on humor to engage students in studies. Even sometimes teachers added humor to bring the students on track when they were found a bit distracted. It worked to make them attentive in class.

Kosiczky \& Mullen (2013) further observed in classes that humor helped teachers building a positive relationship with students. Some teachers shared the humorous stories related to behavior; they told those stories to improve the behavior of students in an indirect way. The teachers connected humorous stories to the target content which helped students remember the content. All teachers were of the opinion that humor could be beneficial for teaching students from different cultures. Moreover, this could improve students' grades when they find studies interesting, and humor could work in this case.

Likewise, Aboudan (2009) conducted three studies on female students of different levels of UAE English language classes. First study was conducted on a group of 200 female students to know their opinions about how humor affects learning, concentration, and attention. Second study was an experimental study on 160 female learners to know their opinions about how humor affects learners' confidence, their participation, and the atmosphere of class. Third study was to know the effect of humor in teaching; and how it affects memorization, recall, and understanding. Aboudan (2009) found that majority of students liked the use of humor in class. According to $71 \%$ responses, it is helpful to make students understand the difficult material, $99 \%$ participants responded that jokes help improving their concentration in the lecture, and $75 \%$ favored humor to be added periodically. Out of 200 participants, $71 \%$ felt that addition of humor brings a positive change in classroom environment, $85 \%$ of students felt that it improves their confidence to express their views openly. According to $79 \%$ students, humor helps creating a positive and friendly relation between teacher and students, $71 \%$ of participants indicated that it helps reducing their fear of teacher, and $88 \%$ felt that learning atmosphere becomes enjoyable due to humor. The result of experiment also disclosed that teaching difficult material with the addition of humor gave better results than teaching that material without its addition. Aboudan (2009) found that the result of experimental group was better than that of control group regarding learning and recall.

Deiter (2000) surveyed the sample of three classes consisted of 35 students in one classroom, 39 students in second classroom, and 53 students in third classroom to know the views of students regarding the element of humor at Iowa State University, Ames, USA. Overall, Deiter (2000) found an average response from the survey regarding the importance of humor, but still the survey showed that students agreed that they usually skip boring classes. They agreed that they like to attend that class where humor is incorporated in teaching. They agreed that they usually remember the content easily which is taught by incorporating humor. The survey further showed that students agreed that humor could make a strong bond between teacher and student. They agreed that they prefer those teachers who use humor in teaching even if they fail to use it effectively. The students agreed that they do not hesitate asking the questions from that teacher who uses humor in the class. Moreover, students pay more attention in that class where humor is added. Deiter (2000) suggested as an instructor's viewpoint that humor is not only good for students, but for an instructor too who uses it. It could make teaching process enjoyable for them.

Similarly, Nadeem (2012) surveyed 100 prospective teachers of Bachelor of Education (B.ED) and Master of Education (M.ED) programs of a university in Lahore, Pakistan. The study was about the effectiveness of humor in English language classroom. The findings indicated that 78 prospective teachers agreed that they do not like high seriousness. Ninety teachers agreed that they like their language teacher to be smiling and cooperative. Eighty participants responded that teaching language with humor creates a positive atmosphere for learning passionately. Eighty-eight responses were in the favor of smiling teachers instead of the serious teachers, and 89 teachers agreed that doing activities in a language classroom give better results when blended with humor and a soft tone. Eighty participants responded that teaching with a touch of humor is more exciting and result oriented. Eighty-one teachers felt that the addition of humor motivates students to learn a language, and 84 believed that friendly teachers have a good impression on them. Ninety prospective teachers agreed that the harsh behavior of teachers makes students worried about their performance (Nadeem, 2012). 


\section{Research Questions}

- What are the views of MPhil scholars of English department on the use of humor in the English language classrooms in Quetta, Balochistan, Pakistan?

- What are the views of MPhil scholars being a teacher towards using humor in the English language classrooms in Quetta, Balochistan, Pakistan?

- Whether the participants' beliefs match with their teaching practices?

\section{Objectives}

- To explore MPhil scholars' views regarding the use of humor in English language classrooms

- To explore scholars' views being a teacher regarding the use of humor in English language classrooms

- To observe whether the participants' views being a teacher match with their teaching practices

\section{Methodology}

\subsection{Participants}

In the present study, purposive sampling was used. The sample consisted of eight female MPhil scholars of English department that were English language instructors at different institutes. They were selected non-randomly as a sample from two different universities in Quetta, Balochistan. Four participants were from women's university and four from co-educational university. The sample was selected to collect data at two levels; first, their perspectives as MPhil scholar and then as teacher.

\subsection{Sampling Procedure}

First, researchers went to the universities for seeking permission. Through permission letter, the permission was taken from the head of each university's English department. Then each participant was provided consent form. Researchers gave a brief description of the study to participants and answered their questions regarding study. The willing participants were requested to sign the consent form. Their identities were promised to be kept confidential.

The interviews were taken separately from each participant in a separate room so as to avoid disturbance. They were recorded in a recording device. Two interviews were taken in one day and they were in English. The teaching practices of participants were also observed.

\subsection{Instruments}

An interview protocol (Appendix A) was developed to probe participants' views, simultaneously a separate observational checklist (Appendix B) was composed for the observation of the same respondents' teaching practices. The researchers developed the instruments and piloted that with two individuals sharing same traits as were of the sample. A few changes were made in the instruments after pilot testing.

\subsection{Data Analysis}

The interview protocol (Appendix A) consisted of three introductory questions and two probing questions followed to get participants' demographic information and to explore their views about the use of humor in English language classroom. Furthermore, all participants' classrooms were observed by following an observational checklist (Appendix B) to compare their views with their teaching practices. Data were analyzed through content analysis since the study was qualitative. NVivo (Version 10) was used for transcribing the interviews and generating categories. Member checking was done for the validity of data.

\section{Results and Discussion}

There were two parts of the interviews: first part consisted of introductory questions and second part consisted of probing questions. Introductory questions were formulated to obtain participants' demographic information (Table 1). Jacob \& Furgerson (2012) believe that asking the participants about their background is a way to warm up them.

Table 1 is providing the background information of participants who were the MPhil scholars of English department from two universities: four from co-educational university and four from women's university. Two participants were the English language instructors at girls' school, two at girls' college, and four at women's university. Their teaching experiences ranged from four to thirteen years. They learnt English language through different sources like school, English language institute, teaching, books, and movies. 
Table 1. Demographic information

\begin{tabular}{lllll}
\hline Participants & Studied at & Source of Learning English & Teaching at & Teaching Experience \\
\hline P1 & Co-educational University & School and English language Institute & Girls' College & 4 years \\
P2 & Co-educational University & School and English language Institute & Girls' School & 8 years \\
P3 & Co-educational University & Teaching & Girls' College & 12 years \\
P4 & Co-educational University & Movies and books & Girls' School & 6 years \\
P5 & Women's University & School & Women's University & 4 years \\
P6 & Women's University & English language Institute & Women's University & 3 years \\
P7 & Women's University & English language Institute & Women's University & 13 years \\
P8 & Women's University & School & Women's University & 10 years \\
\hline
\end{tabular}

There were two probing questions, which were formulated to probe participants' views on the use of humor in the English language classroom.

The first question was about participants' experience being a student regarding humor. They were asked if they had ever experienced being a student that the use of humor motivated them in class. Six categories: confidence booster, increased participation, active learners, teacher-student bonding, interest developer, and memory retention were developed on the basis of participants' responses being a student.

Five participants (P1, P2, P3, P4, and P8) reported that addition of humor was a kind of confidence booster for them; they all shared their experiences of getting confident due to addition of humor in class. This is very much obvious in the following excerpt:

I felt encouraged and confident because of teacher's addition of humor; and I thought whatever I would say even if it was wrong, she would not say anything to me. (P8)

Four participants (P1, P2, P7, and P8) shared their experiences that addition of humor assisted in teacher-student bonding. They and their class fellows were no more hesitant to ask questions. They used to discuss the topics with the teacher fearlessly due to the teacher's use of humor in class. This is evident in the following statement:

...so it was the attitude of the teacher, it was very friendly and very jolly. You know he was very nice, and actually it removed the distance between teacher and students; and we were no more hesitant to talk to that teacher. (P7)

Three participants (P1, P6, and P7) shared their experience that they became active and energetic learners; and studies became enjoyable for them due to teacher's use of humor in class. This is obvious in the following remark:

...he used to be always very humorous. He knew the students' psyche that in a three-hour class, students definitely be fed up; they would be bored so he used to bring a little bit humor in the class that all the students would laugh and all their sleeps were vanished. (P6)

Three participants (P3, P4, and P7) shared that the addition of humor by teacher motivated them to take interest in the subject. This is evident in following statement:

...we got relaxed, we got motivated, and excited, and we got interested in his subject due to his addition of humor. (P3)

Two participants (P1 and P8) informed that the addition of humor increased their participation in class. This is evident in the following comment:

...he gave us the topic which was really a very funny topic, and it was about wife. So he said, "Whatever you think of this that wives bring happiness or sadness in your life, share." So we were like we were smiling, and we were giving foolish statements also. He was enjoying with us and we were enjoying with him so that was the thing which was really making all the students enjoy the class, and that increased our participation too despite our weak grammar. (P1)

One participant (P5) shared that humor assisted in their memory retention and it became easy to memorize the things related to subject due to addition of humor. This is clear in the following excerpt:

...I just remember that while studying novel in our class, we did not remember the name of characters so then one of our teachers she started calling us with the name of characters, and that was one of humorous gestures. It motivated us to remember the names of the characters easily. (P5)

Participants' responses being a student about use of humor suggest that the addition of humor in classroom 
could enhance students' level of confidence, learning process, and participation. Moreover, it could assist to establish teacher-student bonding, improve retention, and enhance students' interest in certain subject.

The results of participants' beliefs being a student for present study are consistent with some other researchers' findings. For instance, Salehi \& Hesabi (2014) conducted a mixed-method study of 60 participants selected from 80 female students of EFL institute Isfahan after a test. Then they were randomly put in the experimental and the control group. The purpose of the study was to know if the addition of humor in teaching is effective or not. Participants were pre-tested to check their previous knowledge before the treatment. Salehi \& Hesabi (2014) found in post and delayed posttest that experimental group, which was taught through the addition of humor in teaching, performed much better than the control group which was taught through traditional way of teaching without the addition of humor. Salehi \& Hesabi (2014) further found by interviewing 10 randomly selected participants from the experimental group of 30 learners that they paid more attention to the lecture when jokes were added in class. Moreover, the element of humor made the learning process fun and interesting. It lessened the anxiety of students and made them learn effectively. It helped students memorizing the grammatical structures effortlessly. The participants believed that humor is the part of every language, so this could be effectively used in language class to encourage students.

Similarly, Stroud (2013) conducted two surveys of 104 students from six different classes in private Japanese high school who were attending 50 minutes English language class once a week. Each class consisted of around 20 students (male and female). The first survey was conducted to know the students' opinion about the general benefits of humor in class. More than $60 \%$ of the students agreed that humor could bring relaxation and motivate students' participation in class. It could increase retention, enjoyment, and make the classroom atmosphere comfortable. Second survey regarding the teacher-created humor through actions, dialogues, material, and visuals were proved to have a positive effect on learning. The students $(79.8 \%)$ agreed that humor in teachers' actions and dialogues could improve participation. They (73.1\%) agreed that it could bring relaxation in class, and make learning enjoyable (79.9\%).

The second question of present research was about participants' experience being a teacher regarding the use of humor. They were asked if they had ever experienced being a teacher that the addition of humor motivated their students. Seven categories: improved attendance, improved learning process, confidence booster, energy booster, increased participation, improved errors, and interactive atmosphere were developed on the basis of participants' responses being a teacher.

Four participants (P1, P4, P6 and P8) responded that their students get confident and start participating in class whenever they use humor in the class. This is evident in the following statement:

...if student is making some wrong pronunciation or if she is using wrong language so instead of making her feel embarrassed, I just create little bit humor over there. On that, she herself starts laughing at her own mistake and rectifies it. In this way, she never feels embarrassment; even she feels more confident to participate... (P1)

Four participants (P2, P3, P6, and P7) noticed that their students get energetic and it seems to remove boredom whenever they add humor in class. This is observable in the following excerpt:

...I feel like whenever I crack some jokes related to whatever they are producing, that is spontaneous of course, so students enjoy and become fresh and active. It always helps me to remove boredom from the class. (P7)

Three participants (P1, P4, and P7) shared that their addition of humor seems to improve students' attendance in class and they stop skipping the classes. This is very much clear in the following remark:

...they love to attend my class, they don't make holidays. They come to my class because there they understand my lecture and have fun with me also just because I use a lot of humor in the class. (P1)

Two participants (P3 and P4) shared that their addition of humor seems to increase students' participation in class. This is obvious in the following comment:

...my students get motivated due to humor. In my course, there is a book which is of short stories; and they are humorous. So whenever I teach those stories to my students, I notice or I experience that the students become excited, they become motivated; and after reading those short stories, they become so much excited that they themselves start writing notes about that story. They themselves become motivated that they start answering questions; they themselves read the question and answer me. (P3)

Two participants (P6 and P8) shared their experience that the addition of humor seems to create interactive 
atmosphere in class and students become confident to interact with teacher. The following response seems to prove this.

I think in my class, mostly students find me very strict in the beginning. They think that I'm a kind of teacher who scolds them, but as soon as I teach them, they find me a very different person; a person who encourages them and who is not always scolding them. There are some things I do not like, other than that they are free to speak in my class. They share their experience, and I listen to them. I also share examples from my own life and I try to keep things friendly. I try to create light environment in my class through little bit humor so that they do not get scared of me. (P8)

One participant (P1) shared that addition of humor seems to increase students' learning process and they start understanding everything more easily. This is indicated in the following excerpt:

...in my class where I totally use humor, the students enjoy a lot. They wish to take my class; they come to my class because there they understand the topics more easily due to humor. (P1)

Another participant (P5) shared that once she mentioned some funny errors in class which assisted in improving students' errors. Through the addition of funny errors, they got to know about their mistakes and they rectified them in a very light atmosphere. This is noticeable in the following excerpt:

...so once I told them that don't be shy, and feel free to talk in English...then I just started talking exactly in the way they talk; like I was using very wrong English, but the whole class enjoyed...actually I remember this that it actually motivated my students. Few of the students, they even came and said, "Ma'am through this joke we came to know that it was our mistake and now we do not do that." (P5)

The participants' responses being a teacher were not much different from their beliefs being a student. The experiences they shared suggested that they were aware of the value of using humor. Moreover, their responses revealed that they often used humor in their English language classroom to motivate their students.

The participants' classrooms were also observed to check if they incorporate humor in their teaching practices and if the addition of humor really motivates their students as they reported in their interviews.

The observations suggested that all the participants added humor while teaching except one participant (P8). In the classrooms of five participants (P1, P2, P5, P6 and P7), the students also used humor. The use of humor did not seem to be harmful whether used by teachers or students. The teacher and students seemed more energetic and active in those classrooms where it was used excessively. In all classrooms, mostly the addition of humor was unintentional and related to the course content. It was observed that the impact of all kinds of humor was positive and motivating. The addition of humor seemed to keep the environment of the classrooms energetic and lively. The students participated in the classes actively and confidently despite their wrong answers. They seemed attentive, and involved in their studies. There was no negative impact of humor traced in any classroom. In all classrooms where humor was used, the students and teacher seemed happy. On the contrary, the students seemed to be very serious in that classroom where it was not used at all. Students were attentive in that classroom too, but found a little uninterested. Moreover, only two to three students were found participating in that class.

The results from the observations suggested that the teachers certainly used humor in their classrooms to motivate students as they mentioned in their interviews. Moreover, the use of humor did motivate students in the same way as the participants' claimed in the interviews.

The results of classrooms' observations and participants' beliefs being a teacher are consistent with the results of some past studies. For instance, Senior (2001) carried out a qualitative study on 28 experienced English language teachers, and eight groups of adult language learners from five different institutions in Australia. Twenty-eight teachers were interviewed and eight groups of students of twenty-five different nationalities with their two male and six female teachers were observed in the classrooms. The focus of the study was specifically humor, and the role which it plays in establishment and maintenance of class cohesion. Senior (2001) found in the interviews that the teachers believed that humor could create a feeling of togetherness, make students relaxed, and encourage participation of students in class. The results of the observations showed that the teachers added humor to create a friendly and relaxed atmosphere from the beginning that helped in building class cohesion. The students responded positively in that class where teachers added humor. The teachers encouraged those students who had the sense to create humor and the ability to make class laugh which improved class cohesion. In many classes, teachers and students shared jokes. Teachers felt that class cohesion could improve learning. Even some students, who could just speak isolated English words, gave a positive response when humor was added in teaching (Senior, 2001). 


\section{Conclusion}

This study intended to investigate MPhil scholars' views being a student and a teacher regarding the use of humor in the English language classroom. The participants were exclusively asked to share their experiences when being a student, the addition of humor from teacher's side motivated them; and when their addition of humor being a teacher motivated their students. The participants' views and the observations of their classrooms suggest that the addition of humor could motivate the students in many ways. For instance, it could improve their confidence level, improve learning process, assist in memorization, lessen anxiety, improve attendance, improve participation, develop interest, create relaxed environment, instill energy, and establish teacher-student bonding (Deiter, 2000; Kosiczky \& Mullen, 2013; Senior, 2001). Thus, it might be possible that by incorporating the element of humor, the English language teachers may make their teaching more effective instead of relying on the traditional teaching style in the English language classroom in Quetta, Balochistan, Pakistan.

\section{Future Directions}

For the data collection of present study, only female participants were selected as a sample (Aboudan, 2009; Salehi \& Hesabi, 2014). Therefore; for the future studies, the sample of male participants could be selected to examine their perception regarding humor or the sample consists of both (male and female participants) could be selected to compare their views. The sample of MPhil scholars was selected to examine their views regarding using humor. Therefore, it could not be judged if the views of school and college going students could be the same as of MPhil scholars' beliefs. In future, the sample of school and college students could be selected to examine their beliefs about the use of humor. For this study, the class of each participant was observed just once. Thus, it cannot be assumed that they always use the appropriate kinds of humor in their classrooms. Moreover, it cannot be assumed that the use of humor always gives positive results in those classrooms. Therefore, in the future, each classroom could be observed at least for a week to obtain more accurate results.

\section{References}

Aboudan, R. (2009). Laugh and learn: Humor and learning a second language. International Journal of Arts and Sciences, 3(3), 90-99.

Deiter, R. (2000). The use of humor as a teaching tool in the college classroom. NACTA journal, 44(2), 20-27.

Jacob, S. A., \& Furgerson, S. P. (2012). Writing interview protocols and conducting interviews: Tips for students new to the field of qualitative research. The Qualitative Report, 17(42), 1-10. Retrieved from http://www.nova.edu/ssss/QR/QR17/jacob.pdf

Kosiczky, B., \& Mullen, C. A. (2013). Humor in High School and the Role of Teacher Leaders in School Public Relations. Journal of School Public Relations, 34(1), 6-39.

Motlagh, F. G., Motallebzade, K., \& Fatemi, M. A. (2014). On the Effects of Teacher's Sense of Humor on Iranian's EFL Learners' Reading Comprehension Ability. International Journal of Applied Linguistics and English Literature, 3(4), 1-5. http://dx.doi.org/10.7575/aiac.ijalel.v.3n.4p.1

Nadeem, M. (2012). Teaching with humor: A benevolent teaching technique for second language learners in teacher education (A Reflective Study). International Journal of English and Literature (IJEL), 2(4), 89-96.

Salehi, F., \& Hesabi, A. (2014). Impact of teaching grammar through humor on Iranian EFL learners. Theory and Practice in Language Studies, 4(8), 1641-1652. http://dx.doi.org/10.4304/tpls.4.8.1641-1652

Senior, R. (2001). The role of humour in the development and maintenance of class cohesion. Prospect, 16(2), 45-54.

Stroud, R. (2013). The laughing EFL classroom: potential benefits and barriers. English Language Teaching, 6(10), 72-85. http://dx.doi.org/10.5539/elt.v6n10p72

\section{Appendix A}

\section{Interview Protocol}

The purpose of the interview is to explore the perspective of MPhil scholars being a student and a teacher regarding the use and significance of humor.

\section{Section A}

\section{Introductory Questions}

1. From which university have you done your MPhil? 
2. How did you learn English language?

3. Tell me about your English language teaching experience: Where do you teach and how long have you been teaching?

\section{Section B}

\section{Probing Questions}

\section{Participants' views about incorporating humor in English language classrooms}

4. Share your experience if you remember any class when you or your class fellows got motivated due to the addition of humor in English language classroom.

5. Share your experience when being a teacher you motivated your students through the addition of humor.

\section{Appendix B}

\section{Observational Checklist}

The purpose of the observation is to compare participants' views with their teaching practices.

\section{Section A}

Teacher's Name...

Date.

Class Observed.

Time......

Observer's Name.

Number of Students

\section{Section B}

\section{Use of humor in English Language Classroom}

1. Use of humor in classroom by teacher.

2. Use of humor in classroom by students.

3. Teacher's use of humor: intentional or unintentional.

4. Students' use of humor: intentional or unintentional

5. Reaction of students on humor use.

6. Reaction of teacher on humor use.

7. Kind of humor used by teacher.

8. Kind of humor used by students.

9. Motivational impact of humor on students.

10. Negative impact of humor on students.

\section{Comments:}

\section{Copyrights}

Copyright for this article is retained by the author(s), with first publication rights granted to the journal.

This is an open-access article distributed under the terms and conditions of the Creative Commons Attribution license (http://creativecommons.org/licenses/by/4.0/). 